\title{
Correlation of serum biomarkers in prediction of gestational diabetes mellitus
}

\author{
Maya Menon*, M. Alaganandha, Jayanthi Mohan
}

Department of Obstetrics and Gynecology, ESIC Medical College and PGIMSR, KK Nagar, Chennai, Tamil Nadu, India

Received: 18 July 2017

Accepted: 18 August 2017

*Correspondence:

Dr. Maya Menon,

E-mail: mayasree@gmail.com

Copyright: () the author(s), publisher and licensee Medip Academy. This is an open-access article distributed under the terms of the Creative Commons Attribution Non-Commercial License, which permits unrestricted non-commercial use, distribution, and reproduction in any medium, provided the original work is properly cited.

\section{ABSTRACT}

Background: Adiponectin and Leptin are adipokines produced by adipocytes. TNF-alpha and IL-6 are inflammatory cytokines which increases insulin resistance. Decreased adiponectin, increased leptin, TNF-alpha and IL-6 is associated with risk of Gestational Diabetes Mellitus, characterised by glucose intolerance that begins or first recognised in pregnancy leading to maternal and foetal complications. India has a high prevalence of GDM upto $16.55 \%$ by $(2 \mathrm{hr}$ plasma glucose of more than $140 \mathrm{mg} / \mathrm{dl}$ ). We aimed to evaluate whether 'First trimester serum biomarkers predict gestational diabetes mellitus'. The objective of the study was to study the serum biomarkers levels in early pregnancy and predict the risk of developing gestational diabetes mellitus. To study the correlation of serum biomarkers levels in gestational diabetes mellitus.

Methods: The study was conducted between October 2014 to March 2016 in healthy pregnant women aged 20-35 yrs attending the antenatal OPD in ESIC Hospital. Study design: Prospective observational study with three study groups 1. NGT, 2. GDM1, 3. GDM2 with two-time points one at first trimester and other second trimester. Sample size: 125 pregnant women. Work plan: Demographics, baseline characteristics and other clinical risk factors of pregnant women in 1 st trimester who consented for the study, meeting the inclusion criteria are noted. 75 gm OGCT (oral glucose challenge test) done at two-time points first and second trimester in the study groups will be analysed using the DIPSI criteria with a cut-off value $\geq 140 \mathrm{mg} / \mathrm{dl}$ and divided into 3 groups. Serum biomarkers were measured by DRG ELISA method at one-time point in first trimester in all the 3 groups.

Results: The serum levels of adiponectin are comparatively reduced in first trimester GDM1 group. As the difference was not significant with p-value of 0.33 there was no correlation between adiponectin and GDM in our study. Serum leptin is increased in second trimester GDM group but the difference is insignificant with a $p$ value of 0.11 showing no correlation.

Conclusions: Among the cytokines IL- 6 also shows an increasing tendency in both GDM1 (5.9 \pm 0.57$)$ and GDM2 $(6.04 \pm 1.04)$ groups compared to the NGT $(5.82 \pm 0.38)$ group. Serum TNF $\alpha$ is increased in GDM1 (17.29 \pm 17.14$)$ and NGT (17.03 \pm 24.03$)$ compared to GDM2 (13.54 \pm 17.29$)$ group.

Keywords: Gestational Diabetes Mellitus, Serum biomarkers

\section{INTRODUCTION}

Adiponectin and leptin are adipokines produced by adipocytes. ${ }^{1}$ They are used as biomarkers in early detection of gestational diabetes mellitus. TNF-alpha and
IL-6 are inflammatory cytokines which increases insulin resistance. The important metabolic effects of biomarkers in the regulation of insulin sensitivity during pregnancy makes them a conceivable candidate as a regulator of insulin resistance during pregnancy. Decreased 
adiponectin and increased leptin, TNF-alpha, IL-6 is associated with increased risk of gestational diabetes mellitus characterised by glucose intolerance that begins or first recognised in pregnancy leading to both maternal and fetal complications. Adipokines secreted by adipocytes and macrophages also works in an autocrine fashion to further exacerbate adipose tissue inflammation, and decrease muscle and liver insulin sensitivity. Low concentrations of adiponectin, the most abundant adipose-specific protein, occur in obesity and predict both a fall in insulin sensitivity and development of type 2 diabetes mellitus (T2DM). Pregnancy is characterized by a changing inflammatory profile compared to the nonpregnant state, with a fine balance between pro- and antiinflammatory cytokines for normal development. In addition to local $\mathrm{T}$ cells, non-lymphoid tissues including the placenta, and especially trophoblast cells, are major sites of cytokine production in pregnancy with a shift towards $\mathrm{T}$ helper- 2 cytokines that has a protective role in the foetal-maternal relationship and favour normal pregnancy outcomes. Expansion of adipose tissue leads to further increased macrophage recruitment and production of pro-inflammatory cytokines such as TNF- $\alpha$ and IL-6. Obesity and excess weight gain in pregnancy also increase the risk of GDM. ${ }^{2}$ Adipokines have provided novel links between obesity and insulin resistance. The increase in insulin resistance in pregnancy occurs due to hormones released from the foetal-placental unit and maternal fat accretion. Increased insulin resistance also relates to excess lipolysis and release of FFAs from enlarged adipose tissue, and secretion of inflammatory factors and adipokines. Chronic low-grade inflammation in adipose tissue impairs insulin signalling, which further enhances expression of genes encoding proteins implicated in insulin resistance.

Improvement of targeted screening by inclusion of first trimester biomarkers may be feasible, facilitating stratified care and early intervention.

To our knowledge, only few investigators have studied maternal leptin concentrations in GDM women and the related published results are conflicting some crosssectional studies have shown that GDM is associated with lower levels of circulating adiponectin, TNF-alpha, leptin and Interleukin 6 may be elevated in GDM pregnancy.

The purpose of this study was therefore to determine if these cytokines were linked to the insulin resistance and altered in GDM compared to non-diabetic pregnant women. As India has a high prevalence of GDM upto $16.55 \%$, we aimed to evaluate whether there are alterations in biomarkers concentration in gestational diabetes mellitus during first and second trimester of pregnancy.

\section{METHODS}

The study was conducted between October 2014 and March 2016 in healthy pregnant women aged 20-35 years attending the antenatal out-patient department in ESIC hospital. Prospective observational study with three study groups, with two-time points-first and second trimester to detect gestational diabetes mellitus.

- $\quad$ Normal glucose tolerance (NGT)

- Gestational diabetes mellitus 1 (GDM1), OGCT done at $1^{\text {st }}$ trimester patients diagnosed as GDM in $1^{\text {st }}$ trimester

- Gestational diabetes mellitus 2 (GDM2), Repeat OGCT done at 2 nd trimester patients diagnosed as GDM in $2^{\text {nd }}$ trimester.

Keeping the power of the study at $80 \%$ and alpha error at $5 \%$, population correlation coefficient of 0.5 , using the $\mathrm{N}$ master software version.2., sample size calculated to 125 .

Sample size is 125 pregnant women. Demographics (the weight and height were measured and BMI was calculated), baseline characteristics and other clinical risk factors of pregnant women in $1^{\text {st }}$ trimester were measured in pregnant women who consented for the study, meeting the inclusion criteria. We included women of reproductive age without pre-existing diabetes. Patients with pre-eclampsia, chronic hypertension or GDM in index pregnancy or previous pregnancies were excluded. Blood samples were collected during routine blood tests performed at first and second trimester. The protocol was approved by the Institutional Ethical committee at ESIC hospital and all pregnant women gave written informed consent for participation in the study.

4-5 $\mathrm{ml}$ of blood was collected from the study participants were refrigerated and centrifuged at $4{ }^{\circ} \mathrm{C}$. Serum obtained by centrifugation of maternal venous blood was immediately frozen and stored at $-70{ }^{0} \mathrm{C}$ until further analysis on serum biomarkers done. 75 gm OGCT (oral glucose challenge test) done at two-time points first and second trimester in the study groups was analysed using the DIPSI criteria in ESIC Hospital with a cut-off value $>=140 \mathrm{mg} / \mathrm{dl}$ and divided into the above 3 groups. Serum biomarkers were analysed by using DRG ELISA kit.

\section{RESULTS}

125 pregnant women participated in the study which included 72 women with normal glucose tolerance (NGT), 25 had gestational diabetes mellitus (GDM1) in the first trimester and 28 had gestational diabetes mellitus (GDM2) in the second trimester. The baseline characteristics of pregnant women are shown in Table 1.

Data analysis was done using SPSS statistical tool (version 20.0; SPSS, Chicago, IL) and p value less than 0.05 was considered as significant. The concentration of the serum biomarkers in all the three groups were compared by a non-parametric one-way ANOVA (Kruskal-Wallis) test. From Table 2, the serum insulin is significantly increased in gestational diabetics in both first $(7.42 \pm 6.04)$ and second trimesters $(7.71 \pm 10.25)$ 
compared to the normoglycemics. HOMA IR is also elevated in gestational diabetics in both first $(2.83 \pm 2.11)$ and second trimesters $(2.45 \pm 3.36)$ compared to the normoglycemics. Serum cholesterol is relatively increased in GDM1 (165.2 \pm 44.48$)$ and GDM2 (169.1 \pm 27.48$)$ group compared to NGT $(151 \pm 31.57)$.

Table 1: Biochemical and anthropometric characteristics.

\begin{tabular}{|llll|}
\hline Parameters & NGT $(n=72)$ & GDM1 $(n=25)$ & GDM2 $(\mathbf{n = 2 8})$ \\
\hline Age (Years) & $25.64 \pm 3.14$ & $27.6 \pm 3.22$ & $26.61 \pm 3.82$ \\
\hline BMI & $22.21 \pm 3.67$ & $28.22 \pm 3.11$ & $28.57 \pm 3.47$ \\
\hline Systolic Blood Pressure $\mathrm{mmHg}$ & $106.8 \pm 7.84$ & $111.6 \pm 5.54$ & $110.4 \pm 7.93$ \\
\hline Diastolic Blood pressure $\mathrm{mmHg}$ & $69.17 \pm 7.27$ & $71.2 \pm 7.81$ & $72.14 \pm 7.38$ \\
\hline DM /in Family & Nil & Nil & Nil \\
\hline H/O PCOS & Nil & Nil & Nil \\
\hline Bl. glucose1 $(\mathrm{mg} / \mathrm{dl})$ & $100.3 \pm 15.17$ & $159.1 \pm 24.94$ & $128.1 \pm 6.23$ \\
\hline Bl. glucose 2 $(\mathrm{mg} / \mathrm{dl})$ & NA & NA & $145 \pm 3.53$ \\
\hline
\end{tabular}

Table 2: Biochemical markers mean values in all the three groups.

\begin{tabular}{|llll|}
\hline Parameters & NGT $(\mathrm{n}=72)$ & OGCT1 $(\mathrm{n}=25)$ & OGCT2 $(\mathrm{n}=28)$ \\
\hline Serum Insulin $(\mu \mathrm{U} / \mathrm{mL})$ & $5.83 \pm 3.5$ & $7.42 \pm 6.04$ & $7.71 \pm 10.25$ \\
\hline HOMA IR & $1.41 \pm 0.85$ & $2.83 \pm 2.11$ & $2.45 \pm 3.36$ \\
\hline Total Cholesterol $(\mathrm{mg} / \mathrm{dl})$ & $151 \pm 31.57$ & $165.2 \pm 44.48$ & $169.1 \pm 27.48$ \\
\hline TNF-alpha $(\mathrm{pg} / \mathrm{ml})$ & $17.03 \pm 24.03$ & $17.29 \pm 17.14$ & $13.54 \pm 17.29$ \\
\hline IL-6 $(\mathrm{pg} / \mathrm{ml})$ & $5.82 \pm 0.38$ & $5.9 \pm 0.57$ & $6.04 \pm 1.04$ \\
\hline Adiponectin $(\mathrm{ng} / \mathrm{ml})$ & $2.95 \pm 2.27$ & $2.23 \pm 1.08$ & $3.34 \pm 5.04$ \\
\hline Leptin $(\mathrm{ng} / \mathrm{ml})$ & $7.51 \pm 1.65$ & $7.12 \pm 1.66$ & $8.1 \pm 1.12$ \\
\hline
\end{tabular}

Serum TNF $\alpha$ has increased in the 1st trimester and decreased in the second trimester GDM groups, whereas Serum leptin and IL 6 are increased in GDM1 and GDM 2 compared to NGT though the values are not statistically significant (Figure 1).

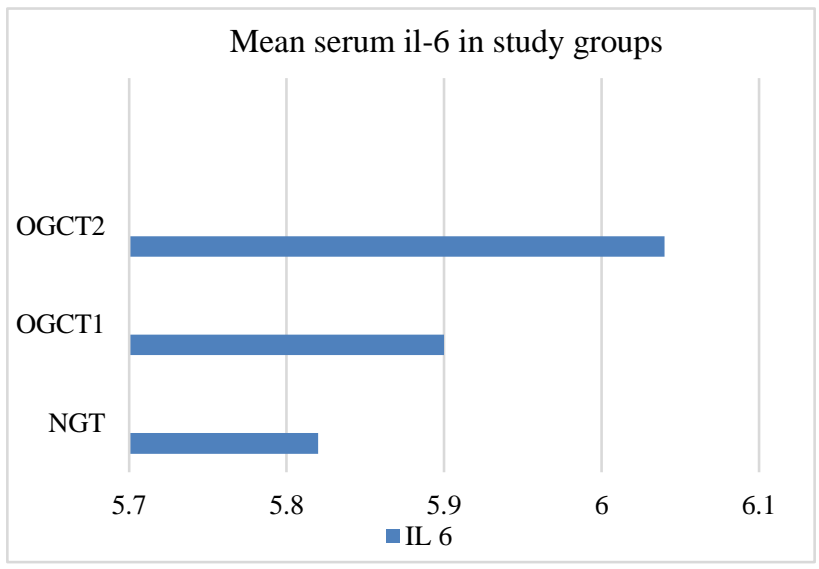

Figure 1: Comparison of mean values of interleukin-6.

Serum adiponectin shows a decreasing trend in GDM1group compared to NGT and on the contrary is increased in GDM2 group. The association of the serum adiponectin, leptin, TNF- $\alpha$, IL-6 with serum total cholesterol, other parameters and cytokines was determined by Spearman's correlation analysis and found no significant correlation.

Multiple logistic regression analysis was also done and found no significant association between biomarkers in the prediction of GDM.

Table 3: There are many studies done to prove correlation of leptin and adiponectin in GDM.

\begin{tabular}{|l|l|}
\hline Study & P-value Leptin/Adiponectin \\
\hline Georgieu et al & $0.05 / 0.001$ \\
\hline Lain K et al & \\
\hline Elham et al $^{12}$ & $0.02 / 0.01$ \\
\hline Saini et al & $0.564 / 0.121$ \\
\hline Sedigheh et al & $0.000 / 0.001$ \\
\hline Skvarca et al & $0.03 / 0.005$ \\
\hline Paradisi et al $^{16}$ & $<0.01 / 0.002$ \\
\hline Kylie et al & $0.238 / 0.238$ \\
\hline Saucedo et al & $1.23 / 0.01$ \\
\hline Our study & $>1.07 / 0.312$ \\
\hline
\end{tabular}

\section{DISCUSSION}

This is a prospective observational study done in 125 healthy pregnant women attending the antenatal OPD in ESICMC and PGIMSR, K. K. Nagar, Chennai tested with $75 \mathrm{gm}$ oral glucose challenge test as per DIPSI guidelines 
and the serum samples of these pregnant women for adipokines were analysed.

In our study, we find in Table 1 that increasing age and BMI are associated with GDM as also evidenced by Frienkel et al, in his study he identified that all the GDM cases were older and heavier than consecutive gravida with documented normal glucose tolerance. ${ }^{3}$

Khan et al in his study concluded that maternal age, BMI, previous history of gestational diabetes and family history of diabetes are the high-risk factors of GDM. ${ }^{4}$

This association of increasing age with GDM might be due to the declining beta cell function and insulin sensitivity. Asian women, develop GDM at a lower BMI due to various reasons like difference in body composition, thrifty gene hypothesis (a genetic tendency to rapidly deposit fat in times of plenty) and changing socio cultural activities like urbanisation. ${ }^{5}$

In our study, serum adiponectin is showing a decreasing trend in first trimester GDM group but the difference is insignificant to find a correlation. This result may be due to inadequate sample size, racial differences, testing methods used in different studies. ${ }^{6}$ Despite gradual decrease in adiponectin along pregnancy, there is no significant alteration in adiponectin levels throughout pregnancy, even though insulin resistance is known to increase dramatically during gestation. A possible explanation for this alleged inconsistency may be an alteration in adiponectin regulation during gestation. Adiponectin expression and secretion have been shown to be subjected to regulation by numerous factors, some of which are possibly affected by the unique hormonal milieu of pregnancy. ${ }^{7}$

Adiponectin on the contrary is increased in GDM2 group. One possible explanation for the higher levels of adiponectin measured during pregnancy may be an increase in adiponectin resistance. Hyperinsulinemic conditions, such as pregnancy, are associated with decreased number of adiponectin receptors, thereby reducing adiponectin sensitivity and this may aggravate insulin resistance. The increase in insulin resistance may lead to compensatory increase in adiponectin levels. ${ }^{8,9}$

These studies have documented that adiponectin has a negative correlation with GDM and leptin has a positive correlation with GDM, and some of these studies have also shown the role of adiponectin as an early predictor for GDM.

There are also studies includes Elham $\mathrm{N}$ et al, Paradisi G et al, Kylie AM et al, Saucedo R et al, Mazaki-Tovi1 S, et al which gives results in accordance to our study with no correlation between serum leptin and adiponectin with $\mathrm{p}$ value more than $0.05 .12,16,17-19$
These above-mentioned studies could not find the correlation between serum adiponectin and GDM thus questioning the predictive nature of serum adipokines. Other cytokines TNF $\alpha$ the inflammatory mediators also show no correlation with the GDM subjects as in our study, which contradicts the result of the study done by Kautzky et al who explained by his study that increased leptin levels in GDM increases insulin resistance by increasing TNF $\alpha$ and IL-6. The study done by Lain K et al shows that adiponectin levels are the same in both GDM and NGT group very similar to our study. Serum IL-6 is slightly elevated in GDM2 compared to NGT and GDM1 as seen in Kautzkyet al. ${ }^{20}$

The reason for this dissimilarity could be due to an altered inflammatory state in pregnancy compared to the non-pregnant state, with a fine balance between pro and anti-inflammatory cytokines for normal fetal development. ${ }^{2}$ This physiological change in pregnancy occurs to prevent fetal allograft rejection. In addition to maternal $\mathrm{T}$ cells placental trophoblasts are major sites for production of these cytokines. Further, increased levels of TNF $\alpha$ and IL-6 occur due to oxidative stress and inflammatory changes produced by hyperglycaemia as in GDM.

In our study, we found that of the adipokines leptin was found to be elevated in GDM2 compared to GDM1 and NGT group with a p value (0.11), adiponectin was reduced only in GDM1 group with p value (0.33), TNF $\alpha$ is almost the same in all the 3 study groups but IL-6 is elevated in first and second trimester GDM group.

\section{CONCLUSION}

Based on our study where we could not find correlation of adipocytokines with GDM. We feel that we need more evidence to decide whether adipocytokines can prove as an existing risk prediction tool in a feasible, practical and cost-effective way. We suggest that future research into adipocytokines and GDM is needed to overcome methodological limitations of already existing studies to provide insights into pathophysiology of GDM and its related complications.

As prevention is always better than cure, we would like to conclude that by optimising an appropriate BMI in prepregnancy state might reduce the incidence of gestational diabetes mellitus in a high-risk population like ours. As pregnancy, itself is a self-inflammatory process these adipocytokines may not be very specific to improve the predictive ability of GDM.

\section{ACKNOWLEDGMENTS}

Authors would like to thank V. Aravindhan (Assistant Professor) Department of Genetics, Taramani for his support during study. 
Funding: No funding sources

Conflict of interest: None declared

Ethical approval: The study was approved by the Institutional Ethics Committee

\section{REFERENCES}

1. Wauters M, Considine RV, and VanGaal LF. Humanleptin from an adipocyte hormone to an endocrine mediator. European $\mathrm{J}$ Endocrinol. 2000;143(3):293-311.

2. Abell SK, De Courten B, Boyle JA, Teede HJ. Inflammatory and Other Biomarkers: Role in Pathophysiology and Prediction of Gestational Diabetes Mellitus. Int J Mol Sci. 2015;16:13442-73.

3. Freinkel N, Metzger BE, Phelps RL, Dooley SL, Ogata ES, Radvany RM, et al. Gestational diabetes mellitus. Heterogeneity of maternal age, weight, insulin secretion, HLA antigens, and islet cell antibodies and the impact of maternal metabolism on pancreatic B-cell and somatic development in the offspring. Diabetes. 1985;34(2):1-7.

4. Khan R, Ali K, Khan Z. Socio-demographic risk factors of Gestational Diabetes Mellitus. Pak J Med Sci. 2013;29(3):843-6.

5. Seshiah V, Balaji V, Balaji MS. Prevalence of gestational diabetes mellitus in south india (Tamilnadu)-a community based study. J Assoc Physicians India. 2008;56:329-33.

6. Khan UI, Wang D, Sowers MR, Mancuso P, Eversonrose SA, Scherer PE, et al. Race-ethnic differences in adipokine levels: The Study of Women's Health Across the Nation. Metabolism. 2012;61:1261-69.

7. Gavrila A, Chan JL, Yiannakouris N. Serum adiponectin levels are inversely associated with overall and central fat distribution but are not directly regulated by acute fasting or leptin administration in humans: cross-sectional and interventional studies. J Clin Endocrinol Metab. 2003;88:4823-31.

8. Lappas M, Yee K, Permezel M, Rice GE. Release and regulation of leptin, resistin and adiponectin from human placenta, fetal membranes, and maternal adipose tissue and skeletal muscle from normal and gestational diabetes mellitus-complicated pregnancies. J Endocrinol. 2005;186:457-65.

9. Meller M, Qiu C, Kuske BT, Abetew DF, MuyRivera M, Williams MA. Adipocytokine expression in placentas from pre-eclamptic and chronic hypertensive patients. Gynecol Endocrinol. 2006;22: 267-73.

10. Georgiou HM, Lappas M, Georgiou GM. Screening for biomarkers predictive of gestational diabetes mellitus. Acta Diabetol. 2008;45:157-65.

11. Lain KY, Daftary AR, Ness RB, Roberts JM. First trimester adipocytokine concentrations and risk of developing gestational diabetes later in pregnancy. Clin Endocrinol (Oxf). 2008;69:407-11.

12. Elham N, Nasrin F, Safoura R. Is there any relation between Adiponectin Levels in the first trimester of pregnancy and Gestational Diabetes Scient Open Access J Womens Health Gynaecol. 2016;2(4)32.

13. Saini V, Kataria M, Yadav A, Jain A. Role of leptin and adiponectin in gestational diabetes mellitus. Internet J Medic Update. 2015;10(1):11-4.

14. Sedigheh S, Mahdieh M, Soodabeh R. Maternal serum leptin concentration in gestational diabetes. Taiwanese J Obstetr Gynaecol. 2011;50:149-53.

15. Skvarca A, Tomazic M, Blagus R, Krhin B, Janez A. Adiponectin/leptin ratio and insulin resistance in pregnanct. J Internat Medi Res. 2013;41(1):123-8.

16. Paradisi G, Ianniello F, Tomei C, Bracaglia M. Longitudinal changes of adiponectin, carbohydrate and lipid metabolism in pregnant women at high risk for gestational diabetes Gynecol Endocrinol. 2010; 26(7):539-45.

17. Kylie AM, David N, Alicia J. Do adiponectin, TNFa, leptin and CRP relate to insulin resistance in pregnancy? Studies in women with and without gestational diabetes, during and after pregnancy. Diabetes Metab Res Rev. 2006;22:131-8.

18. Saucedo R, Zarate A, Basurto L, Hernandez M, Puello E, Galvan R, et al. Relationship between circulating adipokines and insulin resistance during pregnancy and postpartum in women with gestational diabetes. Arch. Med. Res. 2011;42:318-23.

19. Mazaki-Tovi1 S, Kanety H, Pariente C. Maternal serum adiponectin levels during human pregnancy. $\mathrm{J}$ Perinatol. 2007;27:77-81.

20. Kautzky-Willer A, Pacini G, Tura A, Bieglmayer C. Increased plasma leptin in gestational diabetes. Diabetologia. 2001;44(2):164-72.

Cite this article as: Menon M, Alaganandha M, Mohan J. Correlation of serum biomarkers in prediction of gestational diabetes mellitus. Int $\mathrm{J}$ Reprod Contracept Obstet Gynecol 2017;6:4402-6. 